Article

\title{
Trap Happiness and Catch Bias in Sea Lamprey Traps
}

\author{
Ulrich G. Reinhardt ${ }^{1, *}$ and Peter J. Hrodey ${ }^{2}$ (I)
}

1 Biology Department, Eastern Michigan University, 441 Mark Jefferson Science Complex, Ypsilanti, MI 48197, USA

2 U.S. Fish and Wildlife Service, Marquette Biological Station 3090 Wright Street, Marquette, MI 49855-9649, USA; pete_hrodey@fws.gov

* Correspondence: ureinhard@emich.edu; Tel.: +1-734-4874398

Received: 15 February 2019; Accepted: 29 May 2019; Published: 12 June 2019

\begin{abstract}
Sampling fish by trapping can lead to biased conclusions about a population. We used catch data to assess differences between two types of traps for adult sea lamprey (Petromyzon marinus), submerged-funnel traps and studded-tile traps, which are angled ramps with trickle flow leading out of the water. The studded-tile trap at one river caught about $50 \%$ more females than the funnel trap. It caught males that had a smaller body size and females with a lower gonado-somatic index (GSI). The likelihood of catching lamprey in the studded-tile trap increased after they had been caught once. This was not the case for the funnel traps, which are used for mark-recapture-based population assessment of invasive sea lamprey in the Great Lakes. The apparent trap response caused by studded-tile traps may have been caused by a behavioral bias, i.e., the traps consistently attracting a subset of the population. Use of the studded-tile trap for population assessment should only be considered after more is known about its recapture bias. The differences between lamprey caught in the two trap types suggests that a variety of trapping methods needs to be employed in order to get a representative sample from a fish population.
\end{abstract}

Keywords: gear selectivity; trapping bias; trap happiness; sex bias; sea lamprey; invasive species; fish passage

\section{Introduction}

Any method of sampling aquatic animals, be it by visual or acoustic means, towed or in stationary gear, is likely to miss a subset of the sampled populations, due to gear selectivity. If sampling is done to determine some characteristic of the animal's population, trapping bias caused by gear selectivity can be an important consideration [1]. One example is mark-recapture techniques for population estimates, which use the repeated trapping of individuals and assume no effect of trapping and tagging on subsequent probability of capture. A recapture bias caused by the trapped animal's behavior after release would lead to a flawed population size estimate [2,3], unless advanced study designs and statistical methods are employed that correct for such bias [4]. When the probability of re-entry into the trap is increased, the bias is often called "trap happiness" and "trap shyness", when the probability is reduced (e.g., $[5,6])$.

The anadromous sea lamprey (Petromyzon marinus) is native to western Europe and Eastern North America, but is an invasive species in the Great Lakes [7]. During their spawning migration, invasive lamprey are caught in large numbers in many streams, especially when weirs or dams cause them to aggregate. Canadian and U.S. federal agencies trap adult sea lamprey, mostly for population assessment purposes, by mark-recapture, and to supply animals for research; however, expansion of trapping is being considered for population control $[8,9]$. Recent investigations have shown that the current trapping program does not remove a sufficient proportion from the population for control 
purposes, which is either due to trap design, trap deployment, or behavior of the lamprey (e.g., limited time spent near the trap entrance) around the traps [10,11].

The aim of this study was to compare a new with an established sea lamprey trapping method. The established method for trapping sea lamprey in the Great Lakes region is a funnel-type trap, which consists of a submerged metal cage with one to four funnel-shaped entrances through which fish enter. Hinged metal curtains on the entrances impede escape. Stream current flowing through the traps serves as an attractant to lamprey, because they have a positive rheotactic response during the spawning migration [8]. Lamprey that encounter the funnel trap enter with a low probability, for reasons that are still poorly understood [10], but the size and sex of the animal appear to not impact the probability of trap entry [11]. Funnel traps are used for mark-recapture-based population assessment. However, no previous study has tested if the funnel trap influences the probability of recapture of marked animals, which could bias the population assessment. The new trapping method under investigation is a design based on eel ladders, which are angled surfaces with a coarse substrate, such as bristles or pegs, which give anguilliform swimmers like lamprey and eels lateral purchase as they swim through $[12,13]$. In some European rivers, substrates with pegs, called "studded tiles", are used for facilitating upstream passage of adult sea lamprey [14-16]. In the Great Lakes studded-tile traps (abbreviated STUDs in this study) are under consideration for supplementing or replacing funnel traps, because STUDs offer perfect trap retention and target species selectivity, unlike funnel traps that require the manual sorting of lamprey from bycatch. STUDs are angled ramps with pegs that the lamprey weave through out of the river and over a lip into a collection basket (Figure 1). Attraction to the entrance of the STUD and guidance into the basket is provided by pumped water flowing down the ramp. While some studies have explored the behavior of lamprey at the STUD [12,17], it is not known if the probability of lamprey passage through a studded-tile substrate is affected by body size, sex, prior experience with the trap, etc. Given the differences in the way the two trap types function, we expect to find differences in the characteristics of the animals they catch. We analyzed the catch of lamprey during their spawning migration in two rivers (Ocqueoc River and Cheboygan River, both in Michigan, United States, Figures 1 and 2) over two years, and specifically addressed the following questions: (1) Do the animals caught in the two trap types differ in terms of sex ratio, body size, or gonado-somatic index (GSI)? (2) Does having been captured by either trap affect the chance of a lamprey being caught again in the same trap if released downstream? To answer these questions, we compared the catch of funnel and studded-tile traps at two rivers in Michigan during two sea lamprey spawning migration seasons. We assessed the sex ratio, body size, and GSI of sea lamprey caught in paired traps. We also marked about a thousand individuals from each trap every year with fin clips and released them to assess the probability of their returning to the same trap. 


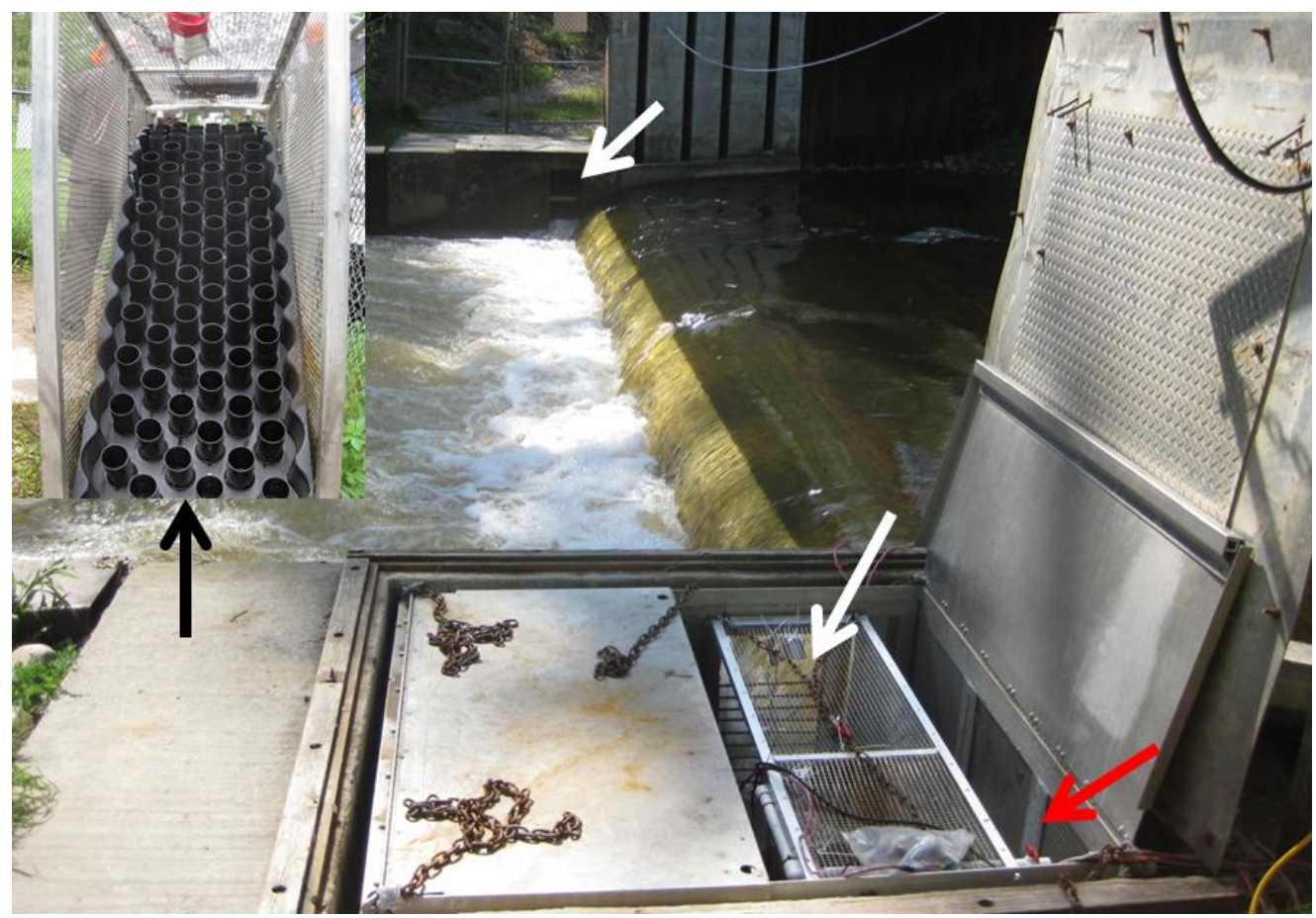

Figure 1. Photograph of the Ocqueoc River low-head electrical weir and sea lamprey traps. One trap bay (shown open in the foreground) contained a studded-tile trap (STUD), and the opposite trap bay contained a stacked funnel made of metal mesh that was fitted to the entrance. Attraction flow to the traps entered the trap bays through an upstream grating at the side of the trap bay (red arrow) and then merged with the mainstream flow after exiting through the trap entrances (white arrows). Ramp flow down the STUD exited the trap bay through the same opening. The insert (black arrow) shows the STUD removed from the bay and without ramp flow.

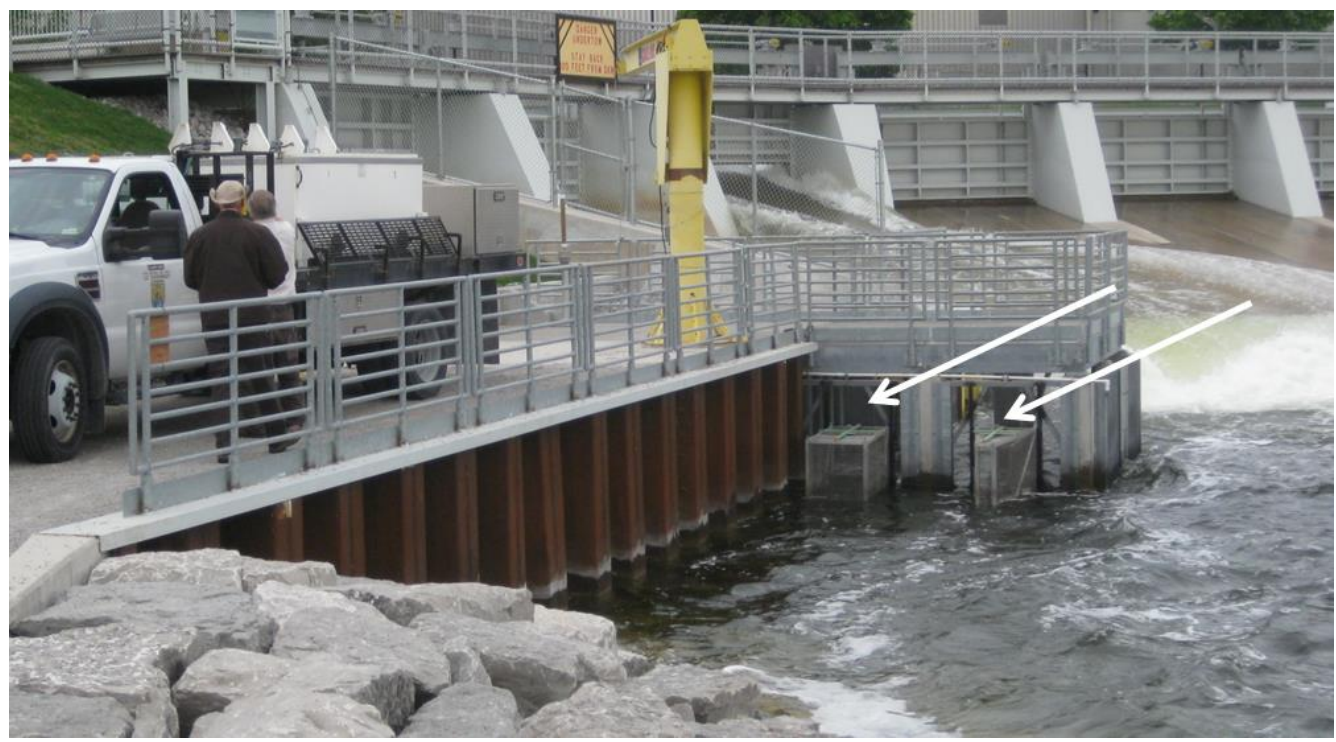

Figure 2. Photograph of the Cheboygan River dam, spillway (background) and trapping facility. Lamprey entered the traps from within a pre-trap bay jutting out into the river, which was made from metal grating and allowed lamprey to enter/exit from three sides. The STUD and adjacent funnel trap (arrows) were attached to the outside of the pre-trap bay and swapped daily. Water from the spillway, STUD ramp attraction flow, and gyre in the river produced a flow pattern within the pre-trap bay that shifted with river conditions. 


\section{Results}

\subsection{Is the Sex Ratio of the Trap Catch Biased?}

Figure 3 and Table 1 give an overview of catch data and the measured characteristics of the trapped lamprey. The combined catch at the two rivers was about 15,000 lamprey in Year 1 and 7500 in Year 2, with differences in the proportion caught by the STUD between the two rivers (Table 1). The run timing varied with fluctuations in water temperature, and included one to several peak nights when up to about $25 \%$ of the annual catch might occur in a single night (Figure 3 ). The high variance in daily catch precluded use of parametric tests in the statistical analysis. In the Ocqueoc River, the sex distribution of the catch was close to 50:50, with little difference between the two trap types (see Table 1; Chi-squared contingency table of catch by sex, comparing the STUD and funnel trap: not significant). In contrast, in the Cheboygan River, the STUD catch was about 60\% females in both years (Table 1), which differed significantly from the sex distribution in the funnel traps of $42 \% / 36 \%$ females in Year 1/Year 2 (Chi-squared contingency table of catch by sex, comparing STUD and funnel trap: $X^{2}=55$ and 111, respectively; d.f. $=1 ; p<0.0001)$. Two additional, larger funnel traps in the vicinity of the Cheboygan traps had a sex ratio of 36\%/37\% females for Year 1/Year 2, based on a catch of about 13,400/10,700 animals in Year 1/Year 2.

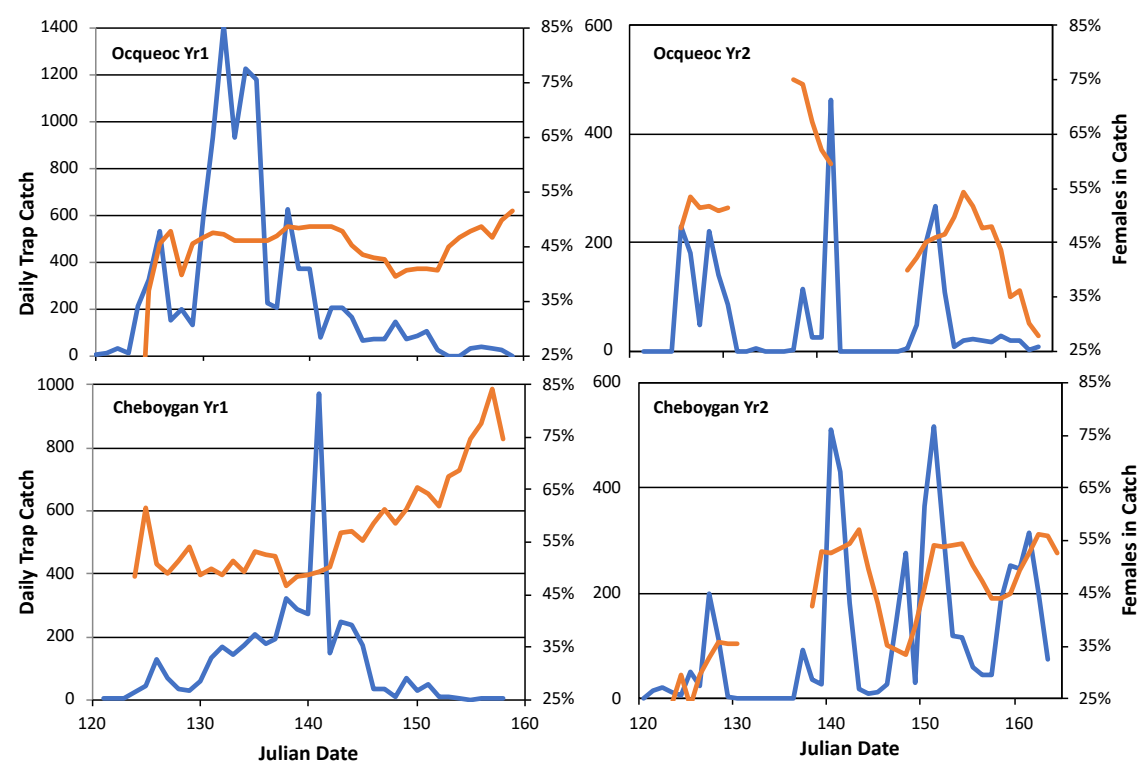

Figure 3. Daily lamprey catch of two experimental traps at Ocqueoc and Cheboygan Rivers (blue line) and percentage of the daily catch that was female lamprey (orange line, five-day moving mean).

Table 1. Summary of catch statistics and characteristics of lamprey caught in two trap types in the Ocqueoc and Cheboygan Rivers. Recapture rates are the percentage of marked fish that returned to both traps combined at each site. Values in parentheses are standard deviations. Blank cells indicate no measurement taken.

\begin{tabular}{ccccc}
\hline & Ocqueoc Year 1 & Ocqueoc Year 2 & Cheboygan Year 1 & Cheboygan Year 2 \\
\hline Total Catch & 11,051 & 2331 & 4513 & 5139 \\
Catch in STUD & $31.1 \%$ & $30.8 \%$ & $64.2 \%$ & $70.7 \%$ \\
Sex by Trap (\% Female) & In STUD: $47 \%$ & In STUD: $51 \%$ & In STUD: $59 \%$ & In STUD: $60 \%$ \\
Fish Marked & In Funnel: $46 \%$ & In Funnel: $49 \%$ & In Funnel: $42 \%$ & In Funnel: $36 \%$ \\
Recapture Rate & 1203 & 790 & 979 & 1460 \\
Mean Body Length & $37 \%$ & $50 \%$ & $18 \%$ & $25 \%$ \\
& & Fem.: $485 \mathrm{~mm}( \pm 36)$ & & Fem.: $486 \mathrm{~mm}( \pm 32)$ \\
Mean Body Weight & & Male: $486 \mathrm{~mm}( \pm 33)$ & & Male: $489 \mathrm{~mm}( \pm 35)$ \\
& & Fem.: $256 \mathrm{~g}( \pm 51)$ & & Fem.: $250 \mathrm{~g}( \pm 47)$ \\
Gonado-Somatic Index & Male: $241 \mathrm{~g}( \pm 53)$ & & Male: $235 \mathrm{~g}( \pm 42)$ \\
& & & Fem.: $21 \%( \pm 3)$ \\
\end{tabular}




\subsection{Is the Trap Catch Biased in Body Size or GSI?}

The sexes differed little in mean body length (Table 1), but females were on average about $6 \%$ heavier (Table 1). In the Ocqueoc River, no significant differences were found in the mean body length or weight of the marked lamprey recaptured from the two trap types (two-way ANOVA on live weight by trap type: sex effect $F_{1,253}=5.02, p=0.026$; trap effect not significant (N.S.); for live length: all effects N.S.).

In the Cheboygan River, the STUD-caught (recaptured) male lamprey were smaller by about $4 \%$ in mean length and $15 \%$ in mean weight than males recaptured in the funnel trap (see Figure 4; two-way ANOVA on live weight by trap type: sex effect $\mathrm{F}_{1,340}=7.6, p=0.001$; trap effect $\mathrm{F}_{1,340}=13.3, p<0.0001$, interaction $\mathrm{F}_{1,340}=13.7, p<0.0001$; on live length: trap effect $\mathrm{F}_{1,343}=11.8, p=0.0007$, other effects N.S.). This pattern of STUD-caught fish being smaller was repeated in the second sample we took, which were the first-time captured lamprey from the Cheboygan River that we also used for the analysis of the gonad-somatic index. STUD-caught lamprey in that sample had a mean thawed length/weight of $445 \mathrm{~mm} / 223 \mathrm{~g}$ standard deviation 32/42), versus $462 \mathrm{~mm} / 245 \mathrm{~g}$ (S.D. 28/43) in funnel trap-caught lamprey (two-way ANOVA on thawed weight by trap type: sex effect $\mathrm{F}_{1,265}=15.7, p=0.0001$; trap effect $\mathrm{F}_{1,265}=7.5, p=0.007$, interaction $\mathrm{F}_{[1,265]}=7.1, p=0.008$; on thawed length: trap effect $\mathrm{F}_{1,339}=19.1$, $p<0.0001$, other effects not significant ).

a)
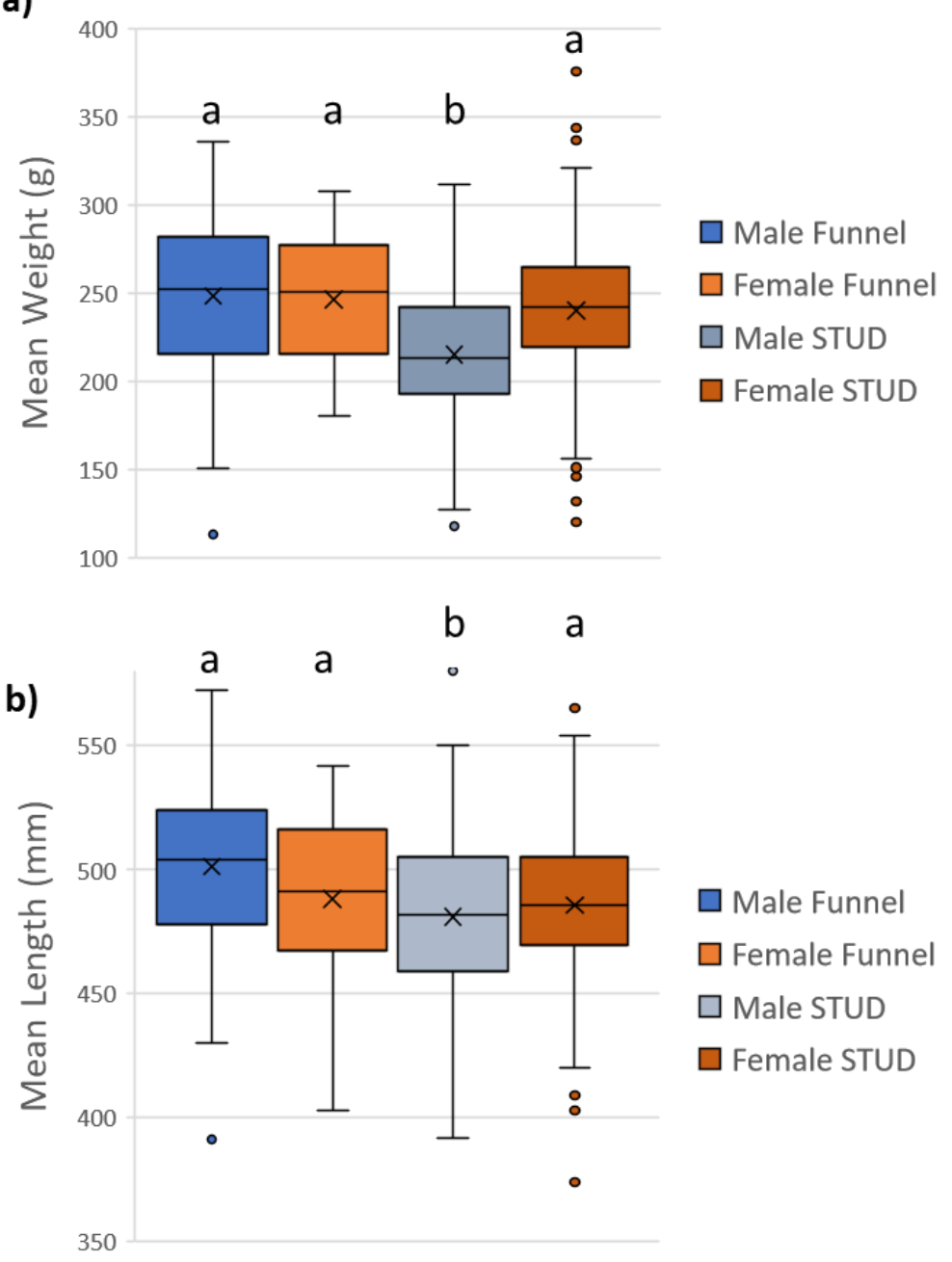

Figure 4. Mean weight (a) and length (b) of sea lamprey recaptured in two trap types in the Cheboygan River. Column marked with different letters had significantly different means in a Tukey's test. 
The mean GSI of females caught in the STUD at the Cheboygan River was $20.9 \%$ (S.D. $=3 \%$, $n=7$ ) versus $22.1 \%$ (S.D. $=3 \%, n=39$ ) for funnel-trap-caught females. This difference was statistically significant. (analysis of covariance (ANCOVA) on female GSI with ordinal date as covariate: $F_{1,153}=4.69, p=0.031$ ). The mean GSI of male lamprey did not differ between trap types (STUD 2.1\%, funnel 2.2\%; $t$-test: $t=0.86$, d.f. $=193$, N.S.).

\subsection{Does Either Trap Type Cause a Recapture Bias?}

The recapture rate of sea lamprey after they were marked by trap type and released varied between sites and years (Table 1). Consistently, the rate of recapture in the STUD surpassed that of the first-time capture: in both rivers and years, individuals caught in the STUD and released after marking returned in greater than expected proportion to the STUD (Table 2). For example, in the Ocqueoc River in Year $1,31 \%$ of the initial catch was retrieved from the STUD, but $41 \%$ of the re-captured animals in that trap had marks, indicating they had previously been caught in the same trap (Table 2). Lamprey first caught in the funnel traps did not show statistically significant changes in the proportion at which marked animals returned to their location of first capture (Table 2).

Table 2. Distribution of lamprey caught, marked, and recaptured in two trap types in the Ocqueoc and Cheboygan Rivers. Column 3 shows the initial distribution of catch in each trap. Column 4 shows by how much the ratio in Column 3 differed in the recaptured individuals (see text for details). The $p$-values are for Chi-squared goodness-of-fit tests.

\begin{tabular}{ccccc}
\hline Location/Year & Trap Type & $\begin{array}{c}\text { Initial Capture } \\
\text { Ratio }\end{array}$ & $\begin{array}{c}\text { Change in Capture Ratio from } \\
\text { Initial Capture to Recapture }\end{array}$ & $p_{\text {(alpha) }}$ \\
\hline Ocqueoc Year 1 & STUD & $31 \%$ & $+10 \%$ & 0.002 \\
& Funnel & $69 \%$ & $+5 \%$ & 0.07, N.S. \\
Ocqueoc Year 2 & STUD & $31 \%$ & $+14 \%$ & $<0.001$ \\
& Funnel & $69 \%$ & $-4 \%$ & N.S. \\
Cheboygan Year 1 & STUD & $64 \%$ & $+12 \%$ & 0.01 \\
& Funnel & $36 \%$ & $+1 \%$ & N.S. \\
Cheboygan Year 2 & STUD & $71 \%$ & $+7 \%$ & 0.04 \\
& Funnel & $29 \%$ & $+5 \%$ & N.S. \\
\hline
\end{tabular}

\section{Discussion}

The two trap types we compared functioned differently, with the STUD at one sampling site catching more females and smaller individuals than the funnel trap. In addition, the STUD also caused a recapture bias. The characteristics of lamprey caught in one or both traps differ from animals-at-large in the population, which could have implications for the assessment and management of invasive sea lamprey in the Great Lakes region. Since a previous study showed no sex or size-biased entry of tagged sea lamprey into funnel traps [11], we conclude that the studded-tile trap probably causes greater gear selectivity than the funnel tap. Our results may also be relevant to adult lamprey fishway structures, such as those for the Pacific lamprey (Entosphenus tridentatus) on the west coast of North America [14,15], as well as the studded-tile substrates used to aid river lamprey (Lampetra fluviatilis) passage in some European rivers [16-18].

The large difference we observed in the sex ratio in the catch between the funnel trap and STUD is difficult to explain, especially since we found it at only one of trapping sites. Experiments on the retention rate of funnel traps [19] showed some level of escapement, but suggested sex-biased entry into the STUD as the more likely explanation for the skewed sex ratio than sex-biased escape from the trap. We do not know why females preferred the STUD and why it showed in only one river. One difference between the rivers was the distance between traps: in the Cheboygan River, the two traps were directly next to each other, and thus presented an immediate choice, while in the other river the lamprey had to travel about $13 \mathrm{~m}$ across the stream to express a choice between traps. Movement patterns of tagged lamprey [19] suggested that only a low proportion of tagged individuals sampled 
both traps at the Ocqueoc location. Therefore, it is possible that an immediate choice is necessary to bring out the sex bias in trap entry. The magnitude of the observed sex bias $(1.5 \times$ greater proportion of females entering the STUD than the funnel trap) argues for further study of behavioral difference between the sexes of sea lamprey in their approach to STUD traps. Studies on studded-tile-based fish passage devices used in European locations [16-18] did not report any sex bias in the approach of tagged river lamprey to the device or in passage efficiency; however, in those studies the studded substrate was fully submerged, whereas in our study the studded ramp was mounted at a steeper angle and had little surface flow. These differences in hydraulic conditions likely cause different challenges for lamprey passage.

We found that body size can also be negatively correlated with trap entry. At the Cheboygan River, where the two trap types were placed next to each other, STUD-caught male lamprey were smaller, while females had a $6 \%$ lower average GSI than their funnel-trapped counterparts. It is possible that larger/heavier or more sexually mature individuals find the climb up the ramp somewhat more difficult, and therefore either attempt the climb at lower numbers or are more likely to abort an attempt. Various migrating finfish species show a positive correlation between body size and successful passage over fishways (e.g., [20,21]). The same holds true for the Pacific lamprey Lampetra tridentata in the Columbia River, where lamprey have to migrate over various dams with fish passage devices [22,23]. In contrast to our study, D'Aguiar [12] did not find an impact of sea lamprey body size on climbing success over a STUD substrate. However, D'Aguiar [12] worked in a lab setting and used different criteria for climbing success, which could explain the difference in the findings. Most fish species never leave the water, and therefore studies on fish climbing or swimming while partially submerged are quite rare (e.g., [24,25]). Baker and Boubee [24] found a positive effect of fish length on climbing success in Inanga (Galaxias maculatus). We could not find any detailed study on the selectivity of the numerous eel ladders employed in Europe and North America [13], nor the studded tiles substrates used to aid lamprey fish passage in Europe [16-18]. Fish passage devices that suppress the passage of larger individuals could have a negative effect on the reproductive potential of a population, because fecundity increases with body size.

In our study, the probability of recapture of marked individuals differed between trap types. For both locations and years, we found significant trap happiness of STUD-caught individuals. Prior studies have investigated the behavioral effects of trapping on fish. For example, Gilbert et al. [6] found that a snapper, Pagrus auratus, became trap-shy after being caught by trawling or angling. Wormald and Steele [7] found trap happiness in tropical snappers (Lutjanus apodus) repeatedly caught in un-baited traps, and discussed how trap happiness can be incorporated into mark-recapture-based population estimates. The funnel traps used in our study did not cause a significant recapture bias, which is good news for the Sea Lamprey Control Program, because it means that one of the key assumptions of the mark-recapture model seems to be met for the trap type the Sea Lamprey Control Program uses for population assessments.

The possible mechanisms causing trap happiness include some behavioral patterns that lead to a higher likelihood of trap entry for a subset of the population, or a change in the behavior of individuals after trapping that makes re-entry into the same trap more likely. Baiting traps with food is known to cause such a change in behavior in some species (e.g., [25]), but in our study neither of the two traps was baited, and both led to similar holding cages that offered no refuge, so it is hard to speculate on what may have attracted lamprey besides water flow. We speculate that a portion of the lamprey population displays a behavioral syndrome that cause it to preferentially enter a certain trap type. Assuming this scenario, sourcing fish from the STUD for mark and recapture in our study entailed marking a biased sample - one that was enriched, relative to the baseline population, for a behavioral pattern that favors entry into the STUD trap. We developed a simple numerical model that shows how a behavioral bias can lead to apparent trap happiness (Figure S1). Consistent behavioral patterns, called temperament [26] or behavioral syndrome when linked in suites of correlated behavior [27], occur in fishes (review in [28]). Fish temperament has consequences for the probability of capture in different 
gear types. For example, Wilson et al. [29] compared the behavior of bluegill sunfish caught by two different techniques, and found a strong correlation between capture technique and a measure of the fish's boldness. Biro [30] found a strong correlation between innate growth rate and capture probability in rainbow trout. Recently, temperament has been shown in lamprey. McLean [9] compared the behavior of migratory-stage adult sea lamprey caught in passive gear and by electrofishing, and found consistent individual differences in the areas of exploration, activity level, and response to a predator stimulus, two of which were correlated with the trapping method. It thus seems plausible that some of the differences we found between STUD and funnel-caught lamprey are a consequence of temperament.

We think that the role of fish temperament deserves more attention from researchers concerned with fish passage or trapping for research purposes. Biased capture can lead to faulty research results-for example, a flawed population assessment-while biased fish passage could cause unwanted selection for certain characteristics, such as smaller size or a bolder behavioral type. Specific to the Sea Lamprey Control Program, our findings suggest that lamprey destined for research purposes should be caught with a variety of gear, in order to maximize the chance of working with a sample representative of the whole population of interest. Further study should test for recapture bias in funnel traps at other locations and explore if the recapture bias could impact the population assessment of invasive sea lamprey.

\section{Materials and Methods}

\subsection{The Trapping Sites}

The traps were deployed by staff from the U.S. Fish and Wildlife Service (USFWS) Sea Lamprey Control Program Alternative Control and Evaluation Unit in two streams in Michigan during the spawning run of May-June 2012 and 2013. Site One, the Ocqueoc River combination low head barrier and electrical weir (turned on only during flood events), is located about $6 \mathrm{~km}$ upstream of the mouth of the Ocqueoc River in Presque Isle County, Michigan, United States $\left(45^{\circ} 29^{\prime} \mathrm{N}, 84^{\circ} 05^{\prime} \mathrm{W}\right)$. Identical concrete trapping bays containing lamprey traps are located at either side of a $13 \mathrm{~m}$-wide weir (Figure 1). One STUD was installed inside the trapping bay, so that entering fish would encounter the STUD trap entrance in the same manner as they would encounter the funnel trap on the opposite side of the river. The traps were portable and switched daily between the left and right bank. Site Two, the Cheboygan Dam and sea lamprey trapping facility, is located about $2.5 \mathrm{~km}$ upstream of the mouth of the Cheboygan River in Cheboygan County, Michigan, United States $\left(45^{\circ} 38^{\prime} \mathrm{N}, 84^{\circ} 28^{\prime} \mathrm{W}\right)$. A STUD and a funnel trap were installed side-by-side ( $1 \mathrm{~m}$ separation) along one wall of a pre-trap bay at the trap facility (Figure 2). The location of the STUD was swapped daily with the funnel trap, so that any variation in attraction flow was randomized. Attraction flow through the traps varied with river discharge, but the current velocity of the attraction flow was substantially lower at the Cheboygan River traps.

\subsection{The Traps}

The STUD consisted of a ramp originally designed for adult eel passage (Milieu Inc. Montreal, Canada) with a $0.55 \mathrm{~m}$ width and $1.7 \mathrm{~m}$ length, that had $0.05 \mathrm{~m}$ diameter $\times 0.11 \mathrm{~m}$ long PVC pipe sections installed perpendicular to the ramp, at a spacing of $30 \mathrm{~mm}$ between pegs (Figure 1 insert). This peg configuration facilitated lamprey climbing better than wider peg spacing in a previous study [9]. The lower part of the ramp was angled at $45^{\circ}$, and preceded a $0.3 \mathrm{~m}$-long section of ramp substrate that was angled at $10^{\circ}$. The apex of the ramp was supplied with approximately $38 \mathrm{~L} \mathrm{~min}^{-1}$ of trickling water flow via a submersible pump installed below the trap. Lamprey that completed their ascent fell into a submerged wire basket. The funnel traps used for comparisons consisted of stainless-steel wire cages with three stacked funnels tapering to square openings of $00.8 \mathrm{~m} \times 0.08 \mathrm{~m}$. Hinged metal "one-way fingers" allowed entry into the trap, but hindered the escape of fish from the trap. The Cheboygan trapping facility had two additional larger funnel traps about $3 \mathrm{~m}$ away in the 
same trapping bay, which caught between 10,000 and 13,000 additional lamprey each year. That catch was included in the estimated sex ratio for the Cheboygan River, but marked animals retrieved from those traps were not included in any other analysis.

\subsection{Handling of Traps and Lamprey}

The routine marking and daily trapping operation procedures of the USFWS trap crews were followed at both study sites. All traps were serviced daily in the morning. This involved lifting the traps out of the water, removing lamprey and by-catch, counting all fish, checking for recaptured lamprey, isolating a sample to be marked that day, cleaning the traps, and switching the location of the STUD and funnel traps. Each day during the trapping operation, 20 or 30 (Year 1 and 2, respectively) lamprey from both trap types were marked by fin clip and released $5 \mathrm{~km}$ (Ocqueoc) and $1 \mathrm{~km}$ (Cheboygan) downstream at the mouth of the river, which is routine operation for the population assessment program. No unmarked lamprey were released. Fin clips (single notches cut in different parts of the dorsal fin) were applied that allowed distinguishing between trapping location (funnel versus STUD), but not trap location, so they do not allow determining if lamprey returned to a specific location instead of a specific trap. Length (measured on a board to the nearest $5 \mathrm{~mm}$ ) and weight data (to the nearest $0.1 \mathrm{~g}$ ) were collected only for lamprey that had fin clips (i.e., had been recaptured). To gain data for the lamprey entering the traps for the first time, in Year 2 a large sample $(n=350)$ of first-time captured lamprey from the Cheboygan River STUD and funnel traps was collected between May 23 and June 10, from the peak to the latter part of the spawning run, with a range of 3-30 fish collected each day. The lamprey were frozen at $-20^{\circ} \mathrm{C}$ for later analysis of total length (to the nearest $5 \mathrm{~mm}$ ), weight (nearest $0.1 \mathrm{~g}$ ), and gonado-somatic index. The GSI was measured by removing and weighing gonad material from the fish, as described in [31]. It was determined that frozen samples differed in weight and length from fresh samples (thawed fish were on average about $8 \%$ lighter), and therefore data from the thawed and fresh samples (lamprey measured for length and weight while alive) were analyzed separately.

\subsection{Data Extraction and Handling}

For the statistical analysis of sex ratios, lamprey catch numbers for each sex over the whole spawning run were combined and analyzed. For the Ocqueoc River, we used a Chi-squared contingency table to compare the observed numbers of females and males in each trap. For the Cheboygan River, we used a Chi-squared goodness-of-fit test of the observed number of females versus an expected number based on the sex ratio in the catch of all traps at that location combined. For the comparison of body weight and GSI data between traps and sexes, data from all trapping days were combined, and each measured lamprey was considered a replicate. The means of body length and weight were compared separately for the two rivers, using a two-way factorial ANOVA with trap type and sex as independent factors. ANCOVA was used in the comparison of female GSI between traps, because there was a statistically significant increase in the GSI of the females throughout the period of sampling, starting at an average GSI of $19.9 \%$ on May 23 and rising to $21.9 \%$ within three weeks (linear best fit formula for GSI versus Julian date: GSI $=0.112 \times$ date $\left.+4 ; R^{2}=0.04, n=156\right)$. Male GSI was analyzed using a $t$-test. The recapture bias of each trap was assessed by a Chi-squared goodness-of-fit test comparing the observed number of marked lamprey returning to their trap of first capture with an expected number that was based on the proportion of first-time catches entering each trap. Statistical tests were done on Vassar Stats software [32]; values of $p_{(\text {alpha }}<0.05$ were considered significant.

Supplementary Materials: The following are available online at http://www.mdpi.com/2410-3888/4/2/34/s1, Figure S1: Model of catch-recapture distribution of two hypothetical behavioral types that differ in their propensity for trap entry.

Author Contributions: Conceptualization, U.G.R. and P.J.H.; data curation, U.G.R.; formal analysis, U.G.R.; funding acquisition, U.G.R. and P.J.H.; investigation, U.G.R. and P.J.H.; methodology, U.G.R. and P.J.H.; project 
administration, P.J.H.; resources, P.J.H.; writing—original draft, U.G.R.; writing—review and editing, U.G.R. and P.J.H.

Funding: This research was funded by a research grant from the Great Lakes Fishery Commission.

Acknowledgments: Brenna Riley carried out much of the data collection in the field and the analysis of video recordings. Chad Andresen, Sara Ruiter, Dan Kochanski, Ed Benzer, and Bruce Eldridge from the USFWS assisted in trap operation, lamprey tagging, and data collection. Nick Johnson, Scott Miehls, and Tom Binder from the Hammond Bay field station gave useful advice and helped at various stages of the project. A number of undergraduate students from the Biology Department at Eastern Michigan University helped with the analysis of lamprey samples and video: Bianca Sander, Lisa Pashnik, Jessica Noyes, and Micah Corlew. The manuscript benefited from extensive comments on earlier versions by Scott Miehls and three anonymous reviewers.

Conflicts of Interest: The authors declare no conflict of interest. The funders had no role in the design of the study; in the collection, analyses, or interpretation of data; in the writing of the manuscript, or in the decision to publish the results. The findings and conclusions in this article are those of the authors and do not necessarily represent the views of the U.S. Fish and Wildlife Service.

\section{References}

1. Hubert, W.A.; Pope, K.L.; Dettmers, J.M. Passive capture techniques. In Fisheries Techniques, 3rd ed.; Zale, A.V., Parrish, D.L., Sutton, T.M., Eds.; American Fisheries Society: Bethesda, MD, USA, 2012; pp. 223-265.

2. Carothers, A.D. Capture-Recapture Methods Applied to a Population with Known Parameters. J. Ecol. 1973, 42, 125. Available online: http://www.jstor.org/stable/3408 (accessed on 10 February 2019). [CrossRef]

3. Pollock, K.H.; Nichols, J.D.; Hines, J.E.; Brownie, C. Statistical inference for capture-recapture experiments. Wildl. Monogr. 1990, 107, 3-97.

4. Kendall, W.L.; Nichols, J.D.; Hines, J.E.; Brownie, C. On the use of secondary capture-recapture samples to estimate temporary emigration and breeding proportions. J. Appl. Stat. 1995, 22, 751-762. [CrossRef]

5. Gilbert, D.J.; McKenzie, J.R.; Davies, N.M. Evidence from tag recapture experiments that fish learn to avoid fishing gear. J. Agric. Biol. Environ. Stat. 2001, 6, 281-291. [CrossRef]

6. Wormald, C.L.; Steele, M.A. Testing assumptions of mark-recapture theory in the coral reef fish Lutjanus apodus. J. Fish Biol. 2008, 73, 498-509. [CrossRef]

7. Hansen, M.J.; Madenjian, C.P.; Slade, J.W.; Steeves, T.B.; Almeida, P.R.; Quintella, B.R. Population ecology of the sea lamprey (Petromyzon marinus) as an invasive species in the Laurentian Great Lakes and an imperiled species in Europe. Rev. Fish Boil. Fish. 2016, 26, 509-535. [CrossRef]

8. Bravener, G.A.; McLaughlin, R.L. A behavioural framework for trapping success and its application to invasive sea lamprey. Can. J. Fish. Aquat. Sci. 2013, 70, 1438-1446. [CrossRef]

9. McLaughlin, R.L.; Hallett, A.; Pratt, T.C.; O'Connor, L.M.; McDonald, D.G. Research to Guide Use of Barriers, Traps, and Fishways to Control Sea Lamprey. J. Great Lakes Res. 2007, 33, 7-19. [CrossRef]

10. Rous, A.M.; McLean, A.R.; Barber, J.; Bravener, G.; Castro-Santos, T.; Holbrook, C.H.; Imre, I.; Pratt, T.C.; McLaughlin, R.L. Spatial mismatch between sea lamprey behaviour and trap location explains low success at trapping for control. Can. J. Fish. Aquat. Sci. 2017, 74, 2085-2097. [CrossRef]

11. McLean, A.R.; McLaughlin, R.L. Consistent individual differences in sea lamprey (Petromyzon marinus) behaviour: Implications for control via trapping. J. Great Lakes Res. 2018, 44, 482-490. [CrossRef]

12. D'Aguiar, M. The Ability of Sea Lamprey (Petromyzon Marinus) to Utilize Solid Structural Components to Climb Inclined Surfaces. Master's Thesis, University of Guelph, Guelph, ON, Canada, 2011.

13. Solomon, D.J.; Beach, M.H. Fish Pass Design for Eel and Elver (Anguilla anguilla); R\&D Technical Report W2-070/TR; Environment Agency: Bristol, UK, 2004.

14. Daigle, W.R.; Peery, C.A.; Lee, S.R.; Moser, M.L. Evaluation of Adult Pacific Lamprey Passage and Behavior in an Experimental Fishway at Bonneville Dam; US Army Corps of Engineers, Portland District: Portland, OR, USA, 2005.

15. Kemp, P.S.; Tsuzaki, T.; Moser, M.L. Linking behaviour and performance: Intermittent locomotion in a climbing fish. J. Zool. 2009, 277, 171-178. [CrossRef]

16. Tummers, J.S.; Winter, E.; Silva, S.; O’Brien, P.; Jang, M.-H.; Lucas, M.C. Evaluating the effectiveness of a Larinier super active baffle fish pass for European river lamprey Lampetra fluviatilis before and after modification with wall-mounted studded tiles. Ecol. Eng. 2016, 91, 183-194. [CrossRef] 
17. Tummers, J.S.; Kerr, J.R.; O’Brien, P.; Kemp, P.; Lucas, M.C. Enhancing the upstream passage of river lamprey at a microhydropower installation using horizontally-mounted studded tiles. Ecol. Eng. 2018, 125, 87-97. [CrossRef]

18. Vowles, A.S.; Don, A.M.; Karageorgopoulos, P.; Kemp, P.S. Passage of European eel and river lamprey at a model weir provisioned with studded tiles. J. Ecohydraulics 2017, 2, 88-98. [CrossRef]

19. Reinhardt, U.G.; Hrodey, P.J. Field Comparison of Eel-Ladder-Style and Traditional Sea Lamprey Traps; Project Completion Report to the Great Lakes Fisheries Commission: Ann Arbor, MI, USA, 2014.

20. Castro-Santos, T. Quantifying the combined effects of attempt rate and swimming capacity on passage through velocity barriers. Can. J. Fish. Aquat. Sci. 2004, 61, 1602-1615. [CrossRef]

21. Haro, A.; Castro-Santos, T.; Noreika, J.; Odeh, M. Swimming performance of upstream migrant fishes in open-channel flow: A new approach to predicting passage through velocity barriers. Can. J. Fish. Aquat. Sci. 2004, 61, 1590-1601. [CrossRef]

22. Keefer, M.L.; Boggs, C.T.; Peery, C.A.; Caudill, C.C. Factors affecting dam passage and upstream distribution of adult Pacific lamprey in the interior Columbia River basin. Ecol. Fresh. Fish. 2013, 22, 1-10. [CrossRef]

23. Keefer, M.L.; Moser, M.L.; Boggs, C.T.; Daigle, W.R.; Peery, C.A. Effects of Body Size and River Environment on the Upstream Migration of Adult Pacific Lamprey. N. Am. J. Fish. Manag. 2009, 29, 1214-1224. [CrossRef]

24. Baker, C.F.; Boubée, J.A.T. Upstream passage of inanga Galaxias maculatus and redfin bullies Gobiomorphus huttoni over artificial ramps. J. Fish Biol. 2006, 69, 668-681. [CrossRef]

25. Tyrrell, C.L.; Christy, M.T.; Rodda, G.H.; Adams, A.A.Y.; Ellingson, A.R.; Savidge, J.A.; Bischof, R.; Dean-Bradley, K.; Dean-Bradley, K. Evaluation of trap capture in a geographically closed population of brown treesnakes on Guam. J. Appl. Ecol. 2009, 46, 128-135. [CrossRef]

26. Réale, D.; Reader, S.M.; Sol, D.; McDougall, P.T.; Dingemanse, N.J. Integrating animal temperament within ecology and evolution. Biol. Rev. 2007, 82, 291-318. [CrossRef]

27. Sih, A.; Bell, A.; Johnson, J. Behavioral syndromes: An ecological and evolutionary overview. Trends Ecol. Evol. 2004, 19, 372-378. [CrossRef] [PubMed]

28. Conrad, J.L.; Weinersmith, K.L.; Brodin, T.; Saltz, J.B.; Sih, A. Behavioural syndromes in fishes: A review with implications for ecology and fisheries management. J. Fish Biol. 2011, 78, 395-435. [CrossRef] [PubMed]

29. Willson, J.D.; Winne, C.T.; Todd, B.D. Ecological and methodological factors affecting detectability and population estimation in elusive species. J. Wildl. Manag. 2011, 75, 36-45. [CrossRef]

30. Biro, P.A. Are most samples of animals systematically biased? Consistent individual trait differences bias samples despite random sampling. Oecologia 2013, 171, 339-345. [CrossRef] [PubMed]

31. Anderson, R.O.; Gutreuter, S.J. Chapter 15. Length, weight and associated structural indices. In Nielsen; Larry, A., Johnson, D.L., Eds.; Fisheries techniques; American Fisheries Society: Bethesda, MD, USA, 1983.

32. VassarStats: Website for Statistical Computation. Available online: www.vassarstats.net (accessed on 17 May 2019).

(C) 2019 by the authors. Licensee MDPI, Basel, Switzerland. This article is an open access article distributed under the terms and conditions of the Creative Commons Attribution (CC BY) license (http://creativecommons.org/licenses/by/4.0/). 